\title{
The Level of Unmet Need \& Social Correlates: An Experience from a District in West Bengal
}

\author{
Anima Haldar ${ }^{1}$, Baijayanti Baur Bai ${ }^{2}$, Tushar Kanti Saha ${ }^{3}$, Malay Mundle², Urmila Dasgupta ${ }^{4}$ \\ and Sita Chattopadhyay ${ }^{5}$
}

\author{
${ }^{1}$ Community Medicine, Nilratan Sircar Medical College, Kolkata \\ ${ }^{2}$ Dept. of Community Medicine, Medical College, Kolkata \\ ${ }^{3}$ Community Medicine, Nilratan Sircar Medical College, Kolkata \\ ${ }^{4}$ Community Medicine, Calcutta National Medical College, Kolkata \\ 5 Institute of Post Graduate Medical Education Research, Kolkata
}

\section{A B STRACT}

Background: The rampant population growth has been viewed as the greatest obstacle to the economic and social advancement to the majority of people in the underdeveloped world. Objectives: To determine the social correlates of unmet need in a Community setting. Study Design: A cross-sectional, descriptive type of observational study. Methods and Materials: The sampling technique used was a Multistage stratified random sampling. One district was chosen randomly from the 19 in the state of West Bengal, India. Out of total 29 blocks in the district, 3 were selected randomly from different subdivision. From these blocks, 12 villages (4 villages from each block) and 4 urban wards were selected from municipality areas, so total 16 areas selected from the district. In West Bengal unmet need for family planning was $8 \%$ as per NFHS-3 (2005-2006), and considering maximum allowable error (20\%), so minimum sample size works out to be 1150 . From each village/ward, 125 eligible couples were covered, so (16 x 125) total 2000 currently married women of reproductive age constitutes the study population. Statistical Analysis: Proportions and Chi-square test. Results: $13.6 \%$ of currently married women of reproductive age group (15-49 yrs.) experienced unmet need for contraception. Unmet need was more in rural area than urban, lower age group than higher, Muslims than Hindus, lower level of literacy (including illiterates) than higher and also increase of joint families than nuclear families. Conclusion: Social correlates like age, religion, literacy status of respondent, type of family, age at marriage, even literacy status of husband also influenced the unmet need of family planning. Sustained and coherent Behavior Change Communication campaign is required to reduce unmet need.

Keywords: Unmet need, social correlates, Family Planning

\section{INTRODUCTION}

There has been inadequate attention accorded to the problem of alarming population growth and its deleterious effect on the effort of development as well as on the food situation. It is well known that contraception can usher in development. ${ }^{1}$ Many women who are sexually active would prefer to avoid conception, but are actually not using any

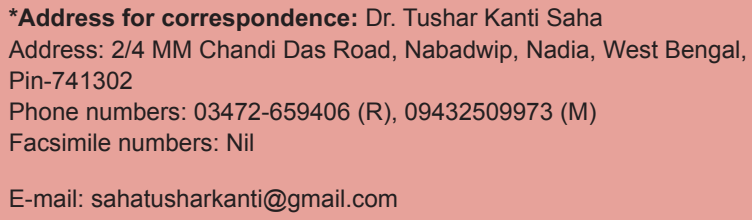

DOI: 10.5530/ijmedph.2.3.7 contraceptive method, including that by their partners. These women are considered to have an unmet need for family planning. ${ }^{2}$ The National Family Health Survey-3 (NFHS-3), data showed contraceptive prevalence in India as $56.3 \%$ and unmet need as high as $12.8 \%$ including $6 \%$ for spacing. ${ }^{3}$ The corresponding figures for unmet need in West Bengal are $8 \%$ and $4 \%{ }^{4}$ In other developing countries the picture is similar. In five Latin American Countries, the level of unmet demands varies from 15\% in Brazil and Colombia, to $21 \%$ in the Dominican Republic. ${ }^{5}$ In another study in Bolivia the unmet need for contraception was $20.6 \%$ though there has been a decline in overall fertility. ${ }^{6}$

A Langer of South America has analyzed in detail the consequences of unwanted pregnancy for which unmet need has been cited as an important factor. ${ }^{7}$ In Korea, the level 
of unmet need was $21 \% .^{8}$ A study of unmet need was carried out among women of reproductive age who attended immunization clinic of Calcutta National Medical College in Kolkata in 2006. ${ }^{9}$ But community based studies in this field have been few. ${ }^{10}$ Socio-cultural and behavioral factors are associated with decision to use and continuation of contraceptive methods and reasons for discontinuation of contraceptives. ${ }^{11}$ The concept of unmet need was developed by Westoff in 1978 and has been refined several times since. ${ }^{12}$ The present study was designed to find out unmet need for family planning and some social correlates among the currently married women of reproductive age group in the district of Paschim Midnapore.

\section{MATERIALS AND METHODS}

This community based cross-sectional study was carried out in rural and urban areas of Paschim Midnapore district of West Bengal, India; during April to September 2009. The sampling technique used was a Multistage stratified random sampling. One district was chosen randomly from the 19 in the state of West Bengal and that district was Paschim Midnapore.

Out of total 29 blocks in the district, 3 were selected randomly from different subdivision, Chandrakona-II in Ghatal subdivision, Keshpur in Sadar subdivision and Nayagram under Jhargram subdivision. In each block, 2 sub centers were selected and from each sub center area, 2 villages were chosen by simple random sampling technique. In the urban agglomerates, two municipalities (Kharagpur and Midnapore) were selected randomly and again 2 wards had been chosen also by simple random sampling technique from each municipality.

Thus we obtained 12 villages (4 villages from each block) and 4 urban wards, 2 from each municipality, (as rural and urban population are in the ratio of $3: 1$, so total 16 areas selected from the district were also distributed in the same ratio i. e. 12 villages from blocks \& 4 urban wards).

In West Bengal unmet need for family planning was $8 \%$ as per NFHS-3 (2005-2006), and considering maximum allowable error $(20 \%)$, so minimum sample size works out to be 1150. Hence the sample size was fixed at 2000 for the present study purpose. From each village/ward, 125 eligible couples were covered, so $(16 \times 125)$ total 2000 currently married women of reproductive age constitutes the study population.

The data were collected using a predesigned and pretested schedule and interviewing the female partner of all eligible couples in a house-to-house survey using standard random procedure to go to the first house. Faculty members of the Community Medicine Department of different Medical Colleges of Kolkata \& Burdwan were involved in the survey. Supervision was done by senior faculty members of Medical Colleges of Kolkata \& Burdwan.

The study variables included age of respondent \& as well as her husband, type of family, Religion, age at marriage, parity, occupation of wife and Husband, literacy status of husband \& wife, per capita monthly income, number of living children, current use of contraceptives, desire for more children or spacing, reasons for non-use of contraceptive methods etc. Data analysis was done by using computer EPI-Info. Statistical test was also done to understand correlation between variables.

*SOCIAL CLASS: *Socio-economic-status of the families was determined from per-capita monthly income. ${ }^{13}$

HIGHER SOCIAL CLASS: Upper middle (Rs. 3,000-4,999), High (Rs. 5,000-9,999), Upper high (Rs. 10,000 and above).

LOWER SOCIAL CLASS: BPL (<Rs. 500), Poor (Rs. 5001,499), Lower (Rs. 1,500-2,999).

CURRENTLY MARRIED WOMEN: Currently married women were taken to mean all women who are at present living with their husbands, irrespective of their parity.

**UNMET NEED FOR FAMILY PLANNING: Women with unmet for family planning for limiting births are those who are fecund and sexually active but are not using any method of contraception, and report not wanting any more children. This is a sub category of total unmet need for family planning, which also includes unmet need for spacing births. The concept of unmet need points to the gap between women reproductive intention and their contraceptive behavior. ${ }^{14}$

\section{RESULTS}

It was revealed from the present study that $13.6 \%$ of the respondents had unmet need for family planning (Fig-I). Areawise variation in unmet need for family planning was found in the present study. Unmet need was greater in rural area $(14.5 \%)$ than urban area $(10.6 \%)$ 


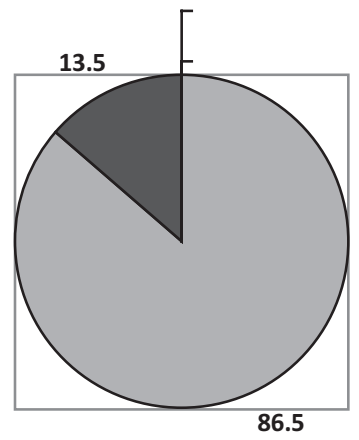

$\square$ No unmeet need

Unmet need

Figure I. Distribution of the respondents according to their unmet need for family planning.

and the difference was statistically significant $(\mathrm{p}<0.05)$. There was also highly significant difference of unmet need among different age groups of the respondents $\left(\mathrm{X}^{2}=44.7, \mathrm{p}=0.0000\right)$ shown in Table-I.
Religion-wise variation in unmet need for family planning was also revealed from Table-I. 21.4\% of Muslim women had unmet need whereas it was $12.5 \%$ in case of Hindu women $\left(X^{2}=15.02, p=0.0001\right)$. Unmet need was more prevalent in joint families $(16.8 \%)$ than nuclear families $(12.3 \%)$ and the difference was statistically significant $(\mathrm{p}<0.05)$.

Highest unmet need (16.7\%) was observed among illiterates $\&$ it was $15 \%$ in case of Just-literate group followed by $12.4 \%, 10.6 \%$ and $10.5 \%$ in case of primary, secondary and graduate \& above groups respectively. Literacy status of women was indirectly proportional to unmet need for family planning as observed from Table-I $(\mathrm{p}<0.05)$.

There was no significant difference of unmet need among different social classes. Unmet need significantly varied

\begin{tabular}{|c|c|c|c|}
\hline \multirow{2}{*}{$\begin{array}{c}\text { Social correlates } \\
\text { I. Area wise }\end{array}$} & \multicolumn{2}{|c|}{ Unmet need } & \multirow[t]{2}{*}{ Test of significance } \\
\hline & No & $\%$ & \\
\hline Rural (1500) & 218 & 14.5 & $X^{2}=4.95, p=0.026$ \\
\hline Urban (500) & 53 & 10.6 & \\
\hline \multicolumn{4}{|l|}{ II. Age } \\
\hline$<18$ yrs (23) & 3 & 13.0 & $X^{2}=44.69, d f=4$ \\
\hline $18-23(452)$ & 89 & 19.7 & $p=0.0000$ \\
\hline \multirow[t]{2}{*}{$24-29(630)$} & 84 & 13.3 & \\
\hline & 65 & 17.1 & \\
\hline$\geq 36(514)$ & 30 & 5.8 & \\
\hline \multicolumn{4}{|l|}{ III. Religion } \\
\hline Hindu (1740) & 217 & 12.5 & $X^{2}=15.02$ \\
\hline Muslim (252) & 54 & 21.4 & $p=0.0001$ \\
\hline Others (8) & 0 & 0 & \\
\hline \multicolumn{4}{|l|}{ IV. Type of family } \\
\hline Nuclear (1394) & 172 & 12.3 & $X^{2}=6.96, p=0.008$ \\
\hline Joint (583) & 98 & 16.8 & \\
\hline Others $(23)$ & 1 & 4.3 & \\
\hline \multicolumn{4}{|c|}{ V. Literacy status of Respondent } \\
\hline Illiterate (588) & 98 & 16.7 & $X^{2}=10.52, d f=4$ \\
\hline Just literate (351) & 53 & 15.1 & $p=0.032$ \\
\hline Primary (436) & 54 & 12.4 & \\
\hline Secondary (568) & 60 & 10.6 & \\
\hline Graduate \& above (37) & 6 & 10.5 & \\
\hline \multicolumn{4}{|l|}{ VI. Social class } \\
\hline Higher social class(122) & 13 & 10.7 & $X^{2}=0.93, p=0.61$ \\
\hline Lower social class(1878) & 258 & 13.7 & \\
\hline \multicolumn{4}{|l|}{ VII. Literacy status of Husband } \\
\hline Illiterate (344) & 47 & 13.7 & $X^{2}=7.84, d f=1$ \\
\hline Just literate (368) & 70 & 19.0 & $p=0.005$ \\
\hline Primary (508) & 59 & 11.6 & \\
\hline Secondary $(636)$ & 79 & 12.4 & \\
\hline Graduate \& above (144) & 16 & 11.1 & \\
\hline \multicolumn{4}{|l|}{ VIII. Age at marriage } \\
\hline$<18$ yrs $(1191)$ & 170 & 14.27 & $X^{2}=3.82, d f=2$ \\
\hline $18-23$ yrs (750) & 96 & 12.80 & $p=0.05$ \\
\hline$\geq 24$ yrs (59) & 5 & 8.45 & \\
\hline
\end{tabular}




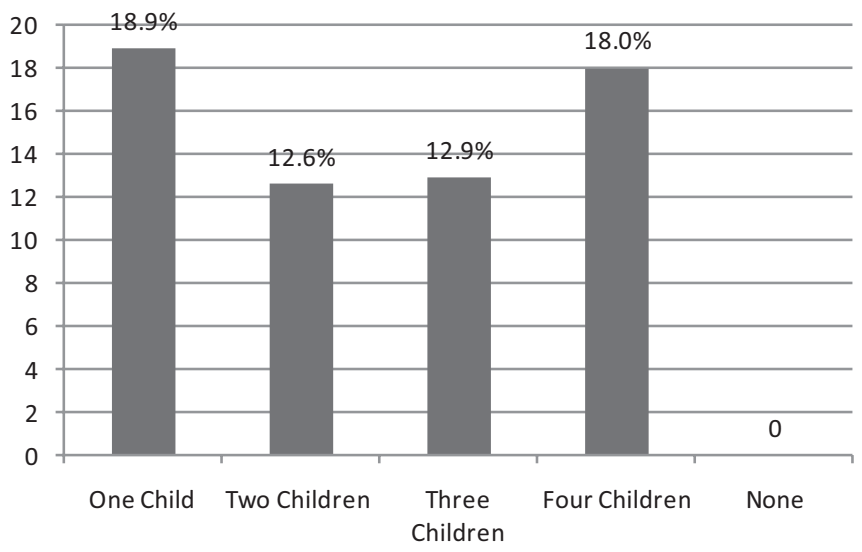

Figure II. Unmet need according to their number of living children.
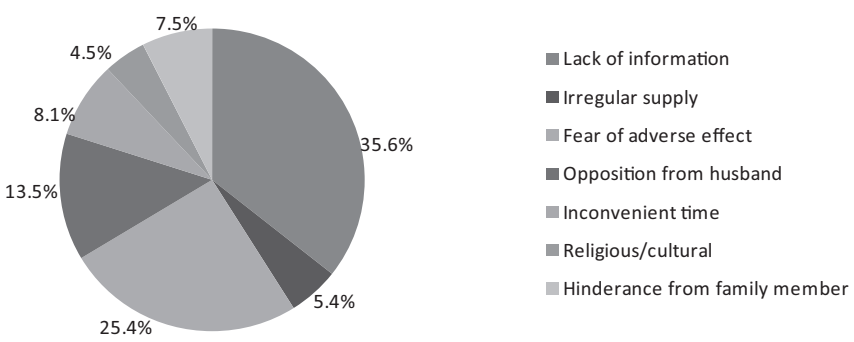

Figure III. Reasons for unmet need.

according to literacy status of the husband of the respondents also as revealed from Table-I. Age at marriage has got some influence on unmet need. It was highest among those who married early than those who married at the age of 24 years and above (Table-I).

Figure-II indicated the unmet need experienced by the respondents according to their number of living children. Unmet need was highest $(18.9 \%)$ among those who had one child followed by $18.0 \%, 12.9 \%$ and $12.6 \%$ in case of women having 4 children, 3 children and 2 children respectively. The major reasons for unmet need were lack of information (35.6\%), fear of adverse effect (25.4\%), opposition from husband (13.5\%), hindrance from elder family members $(7.5 \%)$, inconvenient time $(8.1 \%)$, irregular supply $(5.4 \%)$, religious and or cultural barrier $(4.5 \%)$ shown in Fig-III.

\section{DISCUSSION}

Overall unmet need for family planning was 13.6\% in the present study. The findings of National Family Health Survey-3 (2005-2006) indicate the overall unmet need for family planning in West Bengal was $8 \%{ }^{(4)}$ and in India $12.8 \%{ }^{3}$ Both were less than the findings of the present study. But the findings of the present study did not corroborate with the findings of Bhattacharya et al ${ }^{9}$ where unmet need was quite high $(41.67 \%)$, such difference may be due to the fact that present study was community based with big sample size compared to earlier one was clinic based study with a small sample size.

Earlier study conducted in Uttar Pradesh by Thiagarjan and Adhikari ${ }^{2}$ showed overall unmet need (6.9\%) for family planning among eligible couple by using Westoff's method. ${ }^{5}$

In another community based study conducted by Andurkar et $\mathrm{al}^{10}$ in field practice area of Urban Health Centre under Govt. Medical College of Aurangabad where the unmet need for family planning was much higher $(20.5 \%)$ than the findings of the present community based study.

In the present study it was observed that unmet need for contraception was higher among the rural muslim women, women belonged to illiterate and just literate group, lower literacy status of the husband, joint families and lower age group, and the early age at marriage. Similar findings were also observed by earlier studies., ${ }^{2,15}$ So literacy status of husband, and age at marriage of the respondent was indirectly proportional to the unmet need for family planning. Similar observations also observed by the earlier study. ${ }^{2}$

In the present study $18.9 \%$ of the women of unmet group had one child so it indicates even after first child the women are interested in controlling fertility, this finding did not corroborate with the findings of earlier study ${ }^{15}$ where only $8 \%$ of unmet need group had one child. But there was no apparent relationship between number of living children and level of unmet need.

The main reasons identified by the present study for unmet need were lack of information, fear of adverse effect, opposition from husband, hindrance from elder family members, cultural and or religious barrier. Similar findings were observed by the earlier studies., ${ }^{9,15}$

One important finding of this community based study showed, hindrance from elder members of the family, constitutes for $7.5 \%$ of unmet need for contraception. The main reason for unmet need lack of information/unawareness was quite high $(35.6 \%)$ in the present study in comparison to earlier studies. ${ }^{9,15}$ where lack of information was commented as reason for non acceptance of contraceptive by $24 \%, 26 \%$ of the respondents respectively. This difference may be due to the fact that earlier studies were clinic based one but the present study was community based one.

There were so many social factors like age of currently married women, religion, education, age at marriage etc 
need long term measures to reduce the unmet need but other factors of unmet need can be reduced by providing measures like Behavior Change Communication through mass media and inter- personnel communication.

\section{CONCLUSION}

Social correlates like age, religion, type of family, literacy status and place of residence can affect influenced the unmet need of family planning. Major reasons for unmet need as identified were lack of awareness/information, fear of side effects, opposition from husband, inconvenient time and irregular supply of contraceptives which can be looked into in order to reduce the unmet need for family planning.

\section{REFERENCES}

1. Singh Dr. Karan: Population, the forgotten factor, Quarterly Journal of Public Administration, July-Sep 1992,3; 381.

2. Dr. B.P.Thiagarajan and Mr. Adhikari. The level of unmet need and its determinants in Uttar Pradesh, The Journal of Family Welfare, 1995,41 (4); 66-72.

3. Government of India, IUCD Reference Manual for Medical Officers, Ministry of Health Family Welfare, 2007, Forward, 1-3.

4. NFHS-3 of India, West Bengal, 2005-2006, International Institute for Population Sciences, Mumbai,India; Oct 2008: 3-10.
5. Westoff CF, The potential demand for family planning: new data on unmet needs and estimates for five Latin American Countries, Perspect. Int.Planif. Fam 1988; (Special) (Language Spanish): 2-11. (PMID 12281824 under PubMed).

6. Calle M, Rodrigues RN, Leite Ida C, Unmet need for contraceptive methods in Bolivia,1998,Cad Saude Publica (Language Portuguese); Sept 2006; 22(9) 1989-96.

7. Langer A, Unwanted Pregnancy: impact on health and society in Latin America and the Caribbean, Rev Panam Salud Publica 2002 March; 11(3):192-204 under PMID: 11998185 of PubMed (Language Spanish).

8. Song $\mathrm{KY}, \mathrm{A}$ structural analysis of acceptors and non-acceptors of family planning in remote rural areas, Ingu. Pogon Nonjip, 1983July; 3(1):35-47. (Original article in Korean. English translation under PMID 12339138 of PubMed).

9. S.K. Bhattacharya, Study of unmet need for Family Planning among women of Reproductive age group attending Immunization clinic in a Medical college of Kolkata. Indian Journal o Community Medicine, 2006; 31: 73-75.

10. Andurkar SP, Yadav VB, Dalvi SD, Study on unmet need for Family Planning among married women of reproductive age in Urban Health Centre, field practice area of Govt. Medical College, Aurangabad, Indian Journal of Public Health, 2006; 50 (1): 45-6.

11. Salhan S, Triapthi V (2004). Factors influencing discontinuation of intrauterine contraceptive devices: an assessment in the Indian Context. The European Journal of contraceptive and Reproductive Health Care 9(4), 245-59.

12. Westoff CF, New Estimates of Unmet need and the demand for Family Planning DHS Comparative Reports No. 14, office of Population Research, Princeton University, Macro International Inc., Calverton, Maryland USA, December 2006

13. A.K. Agarwal, Social classification. The need to update in the present Scenario, IJCM, 2008, 33(1), 50-1.

14. Biddlecam A, Loaiza E, Unmet need for family planning, Limiting, percentage, Millennium Development Goals Indicators, UNFPA, New York.

15. Ram R. et al, Study of unmet need for family planning among women of reproductive age attending immunization clinic, Kolkata, IJCM, 2000, Vol. 25 (1); 22-5.

16. Bulato RA, Levin A, Bos ER, Green C,: Effective family Planning programmes. Washington DC, World Bank, 1993, 110. 